Educational Research for Social Change (ERSC)

Volume: 5 No. 2, September 2016

pp. 81-95

ersc.nmmu.ac.za

ISSN: 2221-4070

\title{
Two Years Later: Preservice Teachers' Experiences of Learning to Use Participatory Visual Methods to Address the South African AIDS Epidemic
}

Katie MacEntee

McGill University

katherine.macentee@mail.mcgill.ca

\section{Abstract}

South Africa continues to struggle with the world's highest HIV rates, and the country's young people are amongst those most severely affected by this epidemic. The education sector, and especially teachers, are situated to be leaders in the national response and can provide emotional support as well as information on gender, sexuality, and HIV and AIDS. This article explores preservice teachers' experiences two years after participating in the Youth as Knowledge Producers (YAKP) research intervention, which provided them with training and practical experience in participatory visual methods for HIV and AIDS education. The article discusses participants' reflections on the methods, the continued influences of YAKP on how they think and approach teaching, and the barriers they experienced in securing further learning in this area. The research concludes that preservice teachers can benefit from short-term training in participatory visual methods for HIV and AIDS education by being exposed to a new pedagogical approach, and suggests further development in the integrated responses of higher education institutions in relation to the preservice teachers' HIV and AIDS education.

Keywords: HIV and AIDS, participatory visual methods, preservice teaching, youth as knowledge producers, teacher education, South Africa

Copyright: (C) 2016 MacEntee

This is an open access article distributed under the terms of the Creative Commons Attribution Non-Commercial License, which permits unrestricted non-commercial use, distribution, and reproduction in any medium, provided the original author and source are credited.

\section{Please reference as:}

MacEntee, K. (2016). Two Years Later: Preservice Teachers' Experiences of Learning to Use Participatory Visual Methods to Address the South African AIDS Epidemic. Educational Research for Social Change, 5(2), 81-95. http://dx.doi.org/10.17159/2221-4070/2016/v5i2a6

\section{Introduction}

South Africa continues to struggle with high rates of HIV and AIDS. The general population has an HIV prevalence rate of $19 \%$ and the annual death rate due to AIDS-related causes is 200,000 (UNAIDS, 2013). Amongst the highest rates globally, 7\% of South African youth between the ages of 15 and 24 
years are HIV positive. They also have the lowest rates (14.3\%) of national ARV treatment exposure (Human Sciences Research Council [HSRC], 2014). In the integrated national and provincial strategies laid out by the Department of Basic Education (DBE), the Department of Higher Education and Training (DHET), and the South African National AIDS Council (SANAC), teachers are thought to be well positioned to respond to the physical, emotional, and pedagogical impact of HIV and AIDS on learners' lives (DBE, 2012; DBE \& DHET, 2011; SANAC, 2011). Specific curricular and professional requirements further outline teachers' responsibilities to address the intersecting influences of gender inequity, HIV stigma, and health behaviour (e.g., condom use, alcohol and drug use) on HIV transmission and prevention (DBE, 2000; 2011a; 2011b). While there are many possible approaches to addressing these issues, this article reports on the findings of a follow-up study with South African preservice teachers who were introduced to participatory visual approaches to HIV and AIDS education. Framing the study theoretically in Mitchell's (2014) concept of the "afterlife" of research interventions, this study asks: "What can we learn about HIV and AIDS education through a follow-up study with individuals previously trained in participatory visual methods?" Taking up the question, this article begins by describing Youth as Knowledge Producers (YAKP) as the research context and my connection to the project. This is followed by an outline of my data collection methods. The findings report on preservice teachers' reflections on learning participatory visual methods for HIV and AIDS education, how they have or plan to integrate these methods into their teaching, as well as on challenges they have experienced in applying a participatory visual approach. The findings are discussed in relation to what they might contribute to the development of HIV and AIDS teacher education.

\section{Teacher Education and HIV and AIDS}

The DBE response to the epidemic is reliant on teachers. This is, however, far from straightforward for teachers themselves. Teaching about sex and the body in its sexualised form can pose fundamental challenges to teachers' identities, and threaten their authority in their classrooms (Baxen, 2010; Baxen $\&$ Breidlid, 2004). In the process of life orientation (LO) teaching, teachers may come into conflict with the nationally prescribed curriculum - which is rights-based and comprehensive-and their personal values about sexuality and gender (Ahmed, Flisher, Mathews, Mukoma, \& Jansen, 2009; Helleve, Flisher, Onya, Mukoma, \& Klepp, 2009). They may also have difficulties responding to the specific needs of learners who, for example, are not able-bodied or heterosexual (Chirawu, Hanass-Hancock, Aderemi, de Reus, \& Henken, 2014; Francis, 2012). The emotional component of talking about relationships, love, illness, and death is often avoided by teachers (Naidoo, 2014). The use of didactic, teacher-centred methods can undermine the learner-centred approach advocated in the LO curriculum (Gibbs, Willan, Jama-Shai, Washington, \& Jewkes, 2015). The dearth of in-service teacher education itself remains an issue. Francis and DePalma (2015), for example, found that many teachers responsible for sexual health education indicated that they have had no training or very minimal training in HIV and AIDS education content and pedagogy.

Preservice teachers should be acquiring teaching knowledge and skills during a 4-year undergraduate, or 1-year postgraduate, programme at a higher education institution (HEI). However, numerous studies on teacher education conclude that HEls are failing to prepare preservice teachers for the evolving South African school system impacted by HIV and AIDS (Clark, 2008; James-Traore, Finger, Daileader Ruland \& Stephanie, 2004; Wilmot \& Wood, 2012). HEls in South Africa typically restrict sexual health education to preservice teachers specialising in LO (UNESCO, 2015), although the Higher Education HIV/AIDS Programme (HEAIDS, 2010) review of 23 South African HEIs' teacher education programmes reported a variety of curriculum approaches, including stand alone modules, targeted integration, and topic integration into teacher practice.

Baxen, Wood, and Austin (2011) presented a review of epistemic approaches to HIV and AIDS in teacher education. They concluded that when HIV- and AIDS-related topics are integrated into HEI 
curricula, they are often presented in a fashion that is decontextualised, objectified, and singular in their conceptualisation of the AIDS epidemic (i.e., HIV and AIDS affects everybody equally). This, they argued, "does little to enable students to think critically about how they may approach HIV and AIDS education in their contexts" (p. 8). Rather, it presents the "teacher-as-knowledge-expert" (p. 5), which can result in teachers being more concerned with their identity as teachers "than with the process and outcome of the pedagogical act" (p. 5).

Recommendations for improving HEIs' HIV and AIDS teacher education include using context-specific content embedded in preservice teachers' lived experiences, employing participatory teaching methods that are active and engaging, and more experiential learning opportunities (Holderness, 2012; Wilmot \& Wood, 2012). Reflexive self-study promotes preservice teachers to examine their beliefs and actions in relation to the epidemic (Masinga, 2014; Pithouse, Mitchell, \& Weber, 2009). Baxen, Wood, and Austin (2011) advocated that teachers need support in critical engagement with what HIV and AIDS has to do with different subjects, the crosscutting and intersectional quality of HIV and AIDS epidemic on South African society as a social issue, and developing an appreciation of topic integration.

\section{Teacher Education and Participatory Visual Methods}

A promising area of research and pedagogy that responds to the criticisms and recommendations outlined above involves teachers learning participatory visual methods. Pithouse-Morgan et al. (2013) argued that participatory visual methods are particularly well suited for "pedagogic and research strategies that aim to reposition teachers' experiences and voices at the centre of teacher development in the age of AIDS" (p. 76). Engaging teachers in, for example, collage, drawing, photography, and video production about their understandings of HIV and AIDS develops their reflexive understandings of the epidemic (de Lange, Mitchell, Moletsane, Stuart, \& Buthelezi, 2006; Khau, Masinga, \& Pithouse, 2008; Pithouse, 2011). Employing participatory visual methods also helps preservice teachers conceptualise how to integrate HIV- and AIDS-related topics into mathematics teaching (van Laren, 2008, 2011a, 2011b; 2014). Incorporating different methods into preservice teachers' practicum experiences has facilitated connections with learners, especially when working in under-resourced rural contexts (Khau, De Lange, \& Athiemoolam, 2013; Raht, Smith, \& MacEntee, 2009; Stuart, Raht, \& Smith, 2011). Artistic products resulting from these projects can be shared with communities to facilitate dialogue and to explore areas of social change (de Lange, 2012).

Several studies, having concluded that research interventions using participatory visual methods make an immediate impression on teachers' professional development, wonder about the long-term impact of the approach. Stuart (2006) asked "how personal engagement with constructing and sharing visual texts will affect teachers' abilities to tackle HIV and AIDS in the classroom" (p. 84). Will, as Mitchell and colleagues predicted (Mitchell, de Lange, \& Moletsane, 2014), teachers take the initiative to start exploring the use of participatory visual methods in their own classrooms? To date, there is no research that follows up with teachers after this type of project. How do teachers' experiences of learning this approach coincide with their subsequent experiences in teacher education? What impressions do they develop of this approach? What challenges did they experience in learning about this approach? Do they integrate the methods into their teaching? When, how, and for what purpose? With these questions in mind, I report on a series of one-on-one photo elicitation interviews with three former 
participants in the project, Youth as Knowledge Producers: Arts-Based Approaches to HIV and AIDS Prevention and Education in Rural KwaZulu-Natal (YAKP). ${ }^{1}$

\section{The Research Study Context}

The project, Youth as Knowledge Producers (YAKP), was carried out between 2008 and 2010 through the Centre for Visual Methodologies for Social Change (CVMSC) at the University of KwaZulu-Natal (UKZN). The concept, youth as knowledge producers, draws on the work of Lankshear and Knobel (2006) to refer to young people's visual media productions as representations of cultural knowledge and resources for social change. According to the research team (CVMSC, 2010), YAKP had three goals: (1) to engender a practice of self-study and reflexivity with regards to preservice teachers' approaches to HIV education, (2) to provide training for preservice teachers in participatory arts-based methodologies for HIV education, and (3) to provide opportunities for preservice teachers, as peer educators, to gain practical experience facilitating these methodologies in different educational contexts.

In 2008, YAKP recruited 20 HIV peer educators in the university's faculty of education. In one semester, the group was trained in collage, drumming, hip-hop, forum theatre, photovoice, and participatory video as means for reflection and pedagogy. In 2009, the research team organised two opportunities for the participants to test facilitating their own participatory visual workshops. The first opportunity consisted of a counselling education class in the faculty of education at UKZN. The second workshop context was organised at a rural high school in Vulindlela approximately two hours' drive from UKZN. For this component, the preservice teachers worked in pairs to carry out participatory visual workshops with learners. In 2010, YAKP organised a 2-day training workshop on collage method attended by 2 of the original participants along with 24 new participants. Members of the YAKP research team invited me, a doctoral student at McGill University in Canada with experience in collage, to train the preservice teachers in collage method and to support five preservice teachers during a 2day workshop conducted with high school learners in Vulindlela. In the week following the workshop, members of the research team, two of the preservice teachers, and I returned to the rural area and the learners presented their collages during school assemblies and at a community event organised for World AIDS Day (MacEntee, 2011).

\section{Research process: A visual approach to studying the afterlife of training in participatory visual methodologies in teacher education}

I collected the data reported on in this article when I returned to UKZN in 2012 to conduct a follow-up study on YAKP. ${ }^{2}$ Over the course of 3 months, I consulted preservice teachers, learners, school principals, and members of the research team. In this article, I refer only to the data related directly to the preservice teachers. With university ethical approval, I located seven former YAKP preservice teacher participants, ${ }^{3}$ three of whom volunteered to participate in the follow up study (one man and two women, all using pseudonyms). David was involved with YAKP from 2008 to 2010. He attended most, if not all, of the YAKP trainings. He cofacilitated the intervention of counselling students at UKZN in 2009, and the collage workshop with learners in 2010. At the time of the follow-up interview, David

\footnotetext{
1 YAKP (2007-2009, Project leader: Jean Stuart) was funded by the South African National Research Foundation (NRF). It also forms two of the sub study areas of the NRF Niche Area grant, Every Voice Counts Project (2007-2012, Project leader: Naydene de Lange).

2 The follow-up study was funded by the Social Science and Humanities Council of Canada, Joseph-Armand Bombardier Doctoral Scholarship.

3 YAKP was unable to provide me with a list of former YAKP preservice teachers and recruitment was done through word of mouth in my network of current and former UKZN students. Four individuals who I contacted could not participate in the study, stating they were too busy with work and family responsibilities.
} 
was a graduate of UKZN's teacher education programme, and was pursuing his master's degree in the same faculty. He was also teaching an Oppression and Diversity module to undergraduate students. Sarah and Monique joined YAKP in 2010. They attended the collage training and cofacilitated the collage workshop. At the time of the follow up study, Sarah was still a preservice teacher in her third of four years in the UKZN Bachelors in Education programme, specialising in languages (English and Afrikaans). Monique was also still a preservice teacher in the final term of the same faculty specialising in drama and sports sciences.

I met with the participants at UKZN for one-on-one interviews. Each interview took a little over two hours. Along with open-ended questions, I incorporated photo elicitation into the interview process. Qualitative interviews are a well-established method in the social sciences, during which researchers and participants are engaged in the mutual construction of knowledge about a given subject or topic (Gubrium \& Holstein, 2002). A narrative interview strategy was used to foreground the participants' reflections. This included asking them to relate a chronology of their involvement with YAKP, starting with how they got involved in YAKP, then moving to discuss what happened at the trainings and workshops, and then what has happened in their teaching or education since YAKP. A sense of the YAKP events from the perspective of the participants emerged as a result of this process. From here, I followed up with questions that asked participants to describe the significance of these events. Other questions enquired more directly about theories of teaching and learning about HIV and AIDS:

- Describe the best way to teach young people about HIV and AIDS.

- Tell me in your own words, what is "youth as knowledge producer"?

- Describe the benefits or risks involved with taking a participatory visual approach to HIV and AIDS education.

The responses were audio recorded and later transcribed for analysis.

Additionally, I used the photo elicitation method, which engages participants in responding to photographs during the interview process (Banks, 2001; Harper, 1986). In the context of the follow-up interviews, I used the photographs as "a kind of memory bookend, a starting point from which to evaluate changes" (Harper, 2002 p. 18). It is important to link photographs to the intentions of the research (Lapenta, 2011) while keeping in mind that participants and researchers may differ in what they find "visually arresting" about given photographs (Orellana, 1999, p. 75). I selected 20 images from an archive of 220 photographs, taken either by members of the YAKP research team or by me, of the 2010 collage training workshop. For the purpose of the elicitation activity, I selected images to give a sense of the range of different YAKP activities and people involved in the project at the time. ${ }^{4}$ I chose a mixture of candid and posed photographs of different YAKP participants (e.g., learners, preservice teachers, facilitators, and researchers) engaged in different YAKP activities (e.g., making collages, working in small groups, looking at collages, and presenting their collages to the larger group). I also included pictures of the collage that the participant made during the training and workshop events. The photographs were displayed on my laptop. This allowed the participants to zoom in on different aspects of the image for closer inspection. For Sarah and Monique's interviews, the photo elicitation activity was used at the start of the meetings. However, since David had been involved with YAKP two years prior to when the photographs were taken, the interview began with questions about past events

4 I did not have access to photographs from events in 2008-2009 therefore, the participants' responses were limited to the 2010 activities. 
and turned to the photographs once David's chronology had reached his remembrance of events in 2010.

\title{
Findings
}

I worked with transcriptions of the audio-recorded interviews. Given that I was only working with three participants and had spent considerable time with each one, I drew on what might be described as a close reading of the transcripts rather than a systematic analysis.

\section{Teachers' experiences of YAKP trainings in comparison with other experiences in HIV and AIDS education}

During the visual interview process, the participants discussed participatory visual methods and HIV and AIDS education in relation to their experiences with YAKP and within the larger HEI context. Although HIV and AIDS interventions have a strong presence on the university campus, the participants described a paucity of HIV and AIDS interventions in teacher education. Sarah explained:

\begin{abstract}
There are a lot of initiatives that happen around campus. Like for instance counselling and testing, you know, you get a lot of that happening around. There's a lot of awareness even through the emails that we get sent. But I mean in teaching itself, no! (p. 24)
\end{abstract}

The participatory visual approach differed from the didactic approach to teacher education they were used to. Sarah was "used to people who come and stand in front of you and just talk talk talk talk." (p. 14). Monique remembered:

Collage and HIV, at first I didn't understand how the two came together. I was just like, ok, what are we doing here, please Katie? And then once we got into it and we saw that art can be, like I don't know, used in a way to explain HIV and AIDS it. . . It opened my mind to, ok, there is not just one way of learning about HIV and AIDS. (p. 4)

Having enjoyed the trainings Monique, like the other two participants, was motivated to get more involved in YAKP and was amongst the first of the preservice teachers to volunteer for the collage workshop in the rural area. During the follow up interview, Sarah stated the training "encouraged me to go and find out more" (p. 9) about HIV and AIDS through independent research. For David, YAKP was "amazing. There was no lecture. I was constructing meaning" (p. 17). He recounted: "We were told about arts-based methodologies and I was automatically drawn to it because I'm interested in how do we communicate this message in a way that would engage people" (p. 16). Of course, not all the preservice teachers participating in YAKP felt the same way. Describing one of her friends who also attended the 2010 collage training, Monique said, "it was as though she walked away from it with nothing" (p. 13).

\section{Preservice teachers' impression of participatory visual approach to HIV and AIDS education}

The preservice teachers appreciated the participatory visual approach to HIV and AIDS education. David exclaimed, "It's exciting. It's fun!" (p. 13). Taking a didactic approach of asking learners questions, Monique felt "the learners were giving me answers that I wanted to hear" (p. 7). At the same time, it was difficult for the beginning teacher to let the learners take the lead: "I thought, urgh, I'm not getting through to this one, because he was so quiet" (p. 7). With some patience, however, Monique was pleased with the outcome: "But after a while, I won't even lie, the way he opened up and spoke [about his collage], it really amazed me" (p. 8). The methods were associated with creating opportunities for the teachers to connect more genuinely, and often on a personal level, with learners. Sarah reflected on her memory of such an interaction with one learner: 
The girl in my collage making group, she was like, "at home a relative or somebody who's actually got the disease, and it's a bit difficult living with that person. You can't eat from the same plate. You can't share the same spoon." You know, stuff like that. It was really hectic. And because, personally, I'd also gone through something like that, you know, I was able to really give her some constructive advice as to the fact that you won't get contaminated by the disease just by sharing the same plate, the same spoon. (p.6)

Sarah appreciated being able to draw on her own experiences and respond with helpful information to the learner's difficult situation. But not all the interactions between learners and preservice teachers during the workshop went as smoothly. During the photo elicitation interview, Monique reflected on one such moment with clarity, identifying first how her perspective of children changed as a result of the interaction, and then admitting the discomfort that was involved during this process:

The pictures that he chose, were mainly like money, jewellery, stuff like that. And I was like, why did you choose these things? And he was like, you know, girls or boys are fools for these things when they don't have them. So they would do practically anything to get these things [referring to transactional sex]. I actually remember these pictures out of everyone that was sitting there, because that was something that I wasn't aware of ... It also made me look at the lens that children-and I say children because they are still in school, their minds are still young - and you think that they are innocent but really they do understand what is happening around them. So that was something that was really shocking for me. (p. 5)

What the learner said about transactional sex in the rural context was unexpected by Monique and made her reassess her perceptions about children and their understandings of the epidemic. She continued in the interview to reflect on this interaction with the boy:

I think at that point in time when I came across this stuff I was more shocked than anything. I won't even lie to you ... I had no response to what he was saying . . . because where I come from was very different ... small things don't amuse us, like clothes and stuff. We get these things, so there is nothing that would draw me towards wanting that, or giving something from myself in order to get that. (p. 5)

Monique admits to having struggled to respond to the learner's collage in the moment because it differed so much from her own experiences growing up. Therefore, the participants appreciated how the participatory visual methods seemed to encourage the learners to open up and talk genuinely about the epidemic. However, the participants also struggled at times to respond to the learners' concerns when they differed from the preservice teachers' own experiences.

\section{Challenges with learning about participatory visual approaches to HIV and AIDS}

The YAKP process was reported to be effective; however, long gaps between events disrupted the participants' sense of momentum and they would have liked more opportunities to familiarise themselves with facilitating the methods. David was frustrated when he stated, "Sometimes because new people were coming in, we had to start all over again" (p. 24) and "How is this project moving from events and coming into a movement?" (p. 14). The participant identified areas where they would appreciate more training. David felt certain methods required more training than others did. Compared to collage and photovoice, he struggled with the technical aspects of participatory video: "I have to practice that a few times. I think that we could have had more training in that, so we would 
remember it for the rest of our lives" (p. 19). Sarah wanted help integrating participatory visual approaches into her language teaching. She wondered:

How can you teach literature in a critical way? What makes learners think about some of the real issues that are affecting them in their lives and also in terms of the bigger picture in terms of the world as well? I mean, that's a really difficult one. (p. 16)

External factors made it difficult for participants to independently continue to integrate participatory visual methods and HIV and AIDS topics into their subsequent learning and practicum experiences. A teacher at Sarah's practicum school made fun of her experimenting with student-centred methods and she felt held back as a so-called training teacher on practicum:

It puts us at a disadvantage because when we go to the school we've always got to be aware of the fact that I have a mentor and I must do everything by the standards this mentor follows. Otherwise, if I don't do that, then my marks or whatever they are, they stand in jeopardy. So there is not a lot that we can do! Especially when we begin talking about big stuff. (p. 24)

The "big stuff," as Sarah called it, is HIV and AIDS and issues relating to sex. David described "a stranglehold on schools" (p. 29) that focused on curriculum content and exams: "Maybe that is something to consider, preparing students for the challenges that come from being agents for social change" (p. 29).

\section{Teachers who have had training in participatory visual methods integrate these methods into their} teaching: A reality or not?

The participants have, or plan to, integrate aspects of the participatory visual approach into their teaching practice. Sarah was committed, when she graduates, to explore creative approaches to education: "Now I'm like, empowered whenever I teach to use creative methods that get learners interested" (p. 17). However, she was less certain that she would be able to find a way to integrate HIV and AIDS topics. Monique was excited to graduate and start teaching her own drama classes, in which she planned on integrating HIV- and AIDS-related topics. David, the only participant who was actively teaching at the time of the interviews, described having used collage and forum theatre in his teaching on diversity, however, he had not tackled the topic, HIV and AIDS, directly. Still, he was adamant that comprehensive HIV and AIDS education should remain a priority in South African teaching:

I feel [HIV and AIDS education] is important because this is Southern Africa, there is a high level of HIV/AIDS and teenage pregnancy, and maybe you want to step in and say, "It's like that in Canada, too" but I seriously doubt that. So people are practicing unsafe sex. So it is absolutely necessary for us to talk about it. (p. 21)

The participants maintained an interest and displayed motivation to integrate the principles of participatory creative approaches. Two of the three participants (Monique and David) also described a commitment, if not in practice then in principle, to addressing HIV- and AIDS-related topics into their teaching. However, since YAKP none of the participants had used participatory visual methods to address HIV and AIDS in their respective teaching experiences. 


\section{Implications of the Study of Afterlife for HIV and AIDS Teacher Education Curriculum}

This follow-up study with YAKP was exploratory. The interview process engaged three former YAKP participants in reflecting on their experiences of learning to use participatory visual methods. I interpreted their reflections by using time as a "mark of influence" (Mitchell, 2014, p. 39). In the process of remembering certain events, the participants were not so much recalling the events in 2008-2010, as they were interpreting them from a situated perspective in 2012, and imbuing them with significance as they related to the progression of their lives. Thus, 2 more years, 10 years, and 20 years later, the same process of recalling and ascribing significance may result in very different understandings, not just of events but of participatory visual methods and HIV and AIDS education as well. This process would reflect changes in the participants' lives, their subsequent professional experiences, as well as changes in the discourses of HIV and AIDS teaching and teacher education. Mitchell (2014) concluded, "What is critical here are the questions that emerge when we do this kind of work and the reminder of the ways in which the work is never really done" (p. 42). With three participants, the research findings are not generalisable. They tended towards positive review of the project and participatory visual methods, although some criticisms are also noted. This may be due to response bias, and the participants' perspectives reported here would be strengthened if compared with the perspectives of participants who dropped out or had more negative impressions of YAKP. As the first study of its kind exploring the longitudinal impact of this type of HIV and AIDS teacher education, the findings point towards various areas for future research and development in HIV and AIDS teacher education.

One area to consider is countering AIDS fatigue. Shefer, Strebel, \& Jacobs (2012) described a culture of AIDS fatigue on university campuses, with students feeling removed and unmotivated to engage in any HIV- and AIDS-related learning. Mitchell and Smith (2003) explained AIDS fatigue as the result of prevention approaches that are disconnected from the lives of young people. The participants I interviewed were overwhelmingly appreciative of the participatory visual approach because it presented new and interesting ways for them, as young people, to construct knowledge about HIV and AIDS. The participants' interest in learning more about the topic as they emerged from the trainingsexemplified in their volunteering to facilitate the YAKP workshops and, in Sarah's case, seek out more information on HIV and AIDS-suggests participatory visual methods are "attention-grabbing" and may have particular value in the earlier stages of teacher education to encourage long-term engagement (Jonker, 2012, p. 94). However, it is also noted that participatory visual methods do not speak to all teachers, as was the case for Monique's friend, and a diversity of approaches is needed. There is much that still needs to be explored with regards to engaging preservice teachers in HIV and AIDS education. For instance, when and under what circumstances do participatory visual approaches work to engage preservice teachers, and when might another approach be more successful? What motivates preservice teachers to voluntarily attend interventions such as YAKP? How might participatory visual methods be presented alongside other approaches to HIV and AIDS education?

A second area of concern links to pedagogy. The participants were struck by the contributions of participatory visual methods to the pedagogies of HIV and AIDS teaching-how they engaged learners and created opportunities for teachers to connect with learners about their lived experiences. The participants' memories of working with learners resemble the types of collaborative reflexive selfstudy described and advocated by Pithouse-Morgan et al. (2013) in their work with teachers, while at the same time reflect the personal and emotionally charged interactions that teachers can experience when addressing HIV and AIDS in schools (Baxen, 2010). Arguably, expecting the unexpected is a critical lesson preservice teachers need to learn, especially as it relates to learner-centred sexual health education. However, further research is needed in order to better understand if exposure to the emotional labour of HIV and AIDS education prepares teachers to respond constructively to similar 
experiences in their future practice. Involving learners in teacher education like this also raises some ethical concerns, such as how to prepare teachers to negotiate individuals' rights to HIV and AIDS disclosure (Holderness, 2012), and the need to adequately prepare teachers to respond constructively to the myriad and potentially contentious issues that learners might raise through the art making process (Stuart, 2010). Therefore, moving ahead with this approach to teacher education, what kinds of preparations are needed to mediate the risks to learners and teachers during these interactions?

Finally, what about the methods themselves, and the context for testing them out? Not all participatory visual methods are equal and some methods, especially those that require specialised technology, might require more training than others. A further area for exploration might consider tactics that teachers could use to incorporate participatory visual methods while working among colleagues who are resistant to new or alternative pedagogies. This type of initiative would need to be sensitive to the power inequality between mentor and apprentice so that practicum grades are not put in jeopardy. Khau, de Lange, and Athiemoolam's (2013) strategy, which paired pre- and in-service teachers to explore the methods together to learn and integrate participatory visual methods, shows some promise in this regard. At the same time, there may be time sensitivities. As a research intervention, YAKP was unable to provide ongoing activities and trainings after 2010 and the participants felt that the sense of momentum that the project established was reduced over time. These challenges were accentuated by the broader HEI context that was reported to provide limited opportunities for further engagement with the topic to preservice teachers who were pursuing specialisations in areas other than LO. HIV and AIDS is not prioritised as a learning area amongst the majority of teacher educators and the topic of integration can seem overwhelming in a curriculum that is already overloaded (HEAIDS, 2010; Holderness, 2012). Following up on their YAKP experiences, participants expressed interest in creative participatory methods and their value in HIV and AIDS education, but they struggled to articulate exactly how they might address HIV and AIDS in their teaching. With the exception of, for example Linda van Laren's (2008; 2011a; 2011b; 2014) work with preservice mathematics teachers, there is a paucity of research exploring how teacher educators might integrate HIV and AIDS education into non-LO curriculum areas. How are HIV and AIDS research intervention findings disseminated and integrated into HEl curriculum development? While it is beyond the scope of this article, there is a clear need to study, for example, the HEAIDS community of practice in HIV and AIDS education, which came out of the HEAIDS (2010) study.

\section{Conclusion}

Addressing teachers' challenges with HIV and AIDS education continues to confound those responsible for the national response to HIV and AIDS. The DBE plans a national rollout of scripted lessons for LO, Grades 7-9 (Jansen, 2015). This decision was based on a report by Douglas Kirby that advocates for curricula that tell teachers "what to do and say" and describes "each activity, the materials needed for the activity, how to complete the activity, how long it would take for the particular facts or pieces of information to be presented, the particular points to emphasise, etc." (as cited in Wood \& Rolleri, 2014, p. 526). Adams Tucker, George, Reardon, and Panday (2016) predicted that these teachercentred activities, developed and tested in Gauteng, will improve "disparities in the quality of LO teachings and improve standardization" (p. 350). Scripted lessons could not be further from YAKP's intentions in exploring participatory visual methods as student-centred and context-responsive pedagogies for HIV and AIDS. The YAKP follow-up study described a process of becoming an HIV and AIDS educator that requires more than learning what to do or say in order to complete an activity. Following up with former YAKP participants who were trained in participatory visual methods draws attention to the lack of HIV and AIDS education for these non-LO preservice teachers, as well as the ways that participatory visual methods can help overcome challenges of AIDS fatigue and HIV stigma in teacher education. The results suggest that experiential education in facilitating participatory visual approaches in a supportive context such as YAKP can allow preservice teachers a space to explore the 
benefits and challenges of taking such an approach. However, they require ongoing support in the technicalities of the methods as well as learning how to respond to different issues that learners might raise. It is unclear whether or not this support is within the capacity of a single, short-term research intervention. Challenges of curriculum integration for the preservice teachers, and at the HEI level for teacher educators, was a significant barrier to the participants' HIV and AIDS education. Nevertheless, having learned about these techniques, they endeavoured to apply aspects of the methods (e.g., the emphasis on learner-centred, critical pedagogies that speak to learners' lives) and they expressed the importance of HIV and AIDS education. Structural barriers in the teacher education programme, such as the influence of mentor teachers who may be less amenable to the inclusion of alternative pedagogies or HIV-topic integration, may impede preservice teachers' ability to apply these methods directly for HIV and AIDS education. In this regard, the 2-year afterlife of YAKP was mixed, with preservice teachers being influenced by some of the intervention's pedagogical ideals but practically limited in their ongoing application, especially as they relate to the integration of HIV and AIDS topics into their teaching practice.

Future research is needed in order to follow up with more practising teachers in order to develop a more generalisable understanding of the influences of research intervention over time on teachers' use of participatory visual methods in HIV and AIDS education. Returning to Mitchell's (2014) idea of the study of the afterlife of interventions, there is a sense that this work can (and should) just go on and on if we are to deepen an understanding of impact. It is with this sentiment in mind that I have raised several questions in the discussion of my findings. While it is not possible to answer these questions here, I conclude by pointing towards possible connections and answers that may be explored in the vast body of literature on preservice or initial teacher education. This includes discussions on the translation of educational theory into pedagogical practice or, as Britzman (1991) highlighted, the problematic "practice makes practice" nature of what can be accomplished in a 4-year Bachelor of Education programme. There are insights to be found in the literature that interrogates everything from teachers' childhood experiences of school (Allender \& Allender, 2006; Mitchell \& Weber, 1999), to the idea of the practicum itself; from types of mentoring available to preservice teachers through associate teachers, to support for associate teachers (Kosnik, 2009). Michael Connelly and Jean Clandinin's (1984) concept of personal practical knowledge is particularly relevant to the questions and issues raised in the interviews. Personal practical knowledge "allows us to talk about teachers as knowledgeable and knowing persons" (Connelly \& Clandinin, 1988, p. 25) who draw on professional and personal landscapes of knowledge in order to sustain their teaching practices (Schaefer, Downey, \& Clandinin, 2014). It is by contextualising the educational process in teachers' past experiences, their present understandings, and their future practice, that HIV and AIDS teaching will be developed.

\section{References}

Adams Tucker, L., George, G., Reardon, C., \& Panday, S. (2016). 'Learning the basics': Young people's engagement with sexuality education at secondary schools. Sex Education, 16(4), 337-352. http://dx.doi.org/10.1080/14681811.2015.1091768

Ahmed, N., Flisher, A. J., Mathews, C., Mukoma, W., \& Jansen, S. (2009). HIV education in South African schools: The dilemma and conflicts of educators. Scandinavian Journal of Public Health, 37(2), 4854. http://dx.doi.org/10.1177/1403494808097190

Allender, D., \& Allender, J. (2006, July-August). How did our early education determine who we are as teachers? Paper presented at the Sixth International Conference on Self-Study of Teacher Education Practices, East Sussex, UK.

Banks, M. (2001). Visual methods in social research. Thousand Oaks, USA: SAGE. 
Baxen, J. (2010). Performative praxis: Teacher identity and teaching in the context of HIV/AIDS. New York, USA: Peter Lang.

Baxen, J., \& Breidlid, A. (2004). Researching HIV/AIDS and education in sub-Saharan Africa: Examining the gaps and challenges. Journal of Education, 34, 9-29.

Baxen, J., Wood, L., \& Austin, P. (2011). Reconsidering and repositioning HIV and AIDS within teacher education. Africa Insight, 40(4), 1-10.

Britzman, D. P. (1991). Practice makes practice: A critical study of learning to teach. Albany, USA: Suny Press.

Centre for Visual Methodologies for Social Change. (2010). Annual Report September 2009-December 2010. Durban, South Africa: University of KwaZulu-Natal.

Chirawu, P., Hanass-Hancock, J., Aderemi, T., de Reus, L., \& Henken, A. (2014). Protect or enable? Teachers' beliefs and practices regarding provision of sexuality education to learners with disability in KwaZulu-Natal, South Africa. Sexuality and Disability, 32(3), 259-277. http://dx.doi.org/10.1007/s11195-014-9355-7

Clark, D. (2008). Heroes and villains: Teachers in the education response to HIV. Paris, France: International Institute for Educational Planning.

Connelly, F. M., \& Clandinin, D. J. (1984). Personal practical knowledge at Bay Street School: Ritual, personal philosophy and image. In R. Halkes \& J. K. Olson, (Eds.), Teacher thinking: A new perspective on persisting problems in education, (pp. 134-148). Heirewig, Netherlands: Swets \& Zeitlinger.

Connelly, F. M., \& Clandinin, D. J. (1988). Teachers as curriculum planners: Narratives of experience. Toronto, Canada: OISE Press.

De Lange, N. (2012). Researching to make a difference: Possibilities for social science research in the age of AIDS. SAHARA-J: Journal of Social Aspects of HIV/AIDS, 9(1), S3-S10. http://dx.doi.org/10.1080/17290376.2012.744897

De Lange, N., Mitchell, C., Moletsane, R., Stuart, J., \& Buthelezi, T. (2006). Seeing with the body: Educators' representations of HIV and AIDS. Journal of Education, 38, 45-66.

Department of Basic Education. (2000). Norms and standards for educators. Retrieved from http://uscdn.creamermedia.co.za/assets/articles/attachments/08137 notice82.pdf.

Department of Basic Education. (2011a). Curriculum and assessment policy statement (Life orientation): Further education and training phase Grades 10-12. Retrieved from http://www.education.gov.za/Portals/0/CD/National\%20Curriculum\%20Statements\%20and\%20V ocational/CAPS\%20FET\%20 \%20LIFE\%200RIENTATION\%20 \%20GR\%201012\%20 \%20WEB E6B3.pdf?ver=2015-01-27-154251-017

Department of Basic Education. (2011b). Curriculum and assessment policy statement (Life orientation): Senior phase Grades 7-9. Retrieved from

http://www.education.gov.za/Portals/0/CD/National\%20Curriculum\%20Statements\%20and\%20V ocational/CAPS\%20SP\%20\%20LIFE\%200RIENTATION\%20\%20WEB.pdf?ver=2015-01-27-160145$\underline{607}$

Department of Basic Education. (2012). Integrated strategy on HIV, STIs and TB, 2012-2016. Retrieved from http://www.education.gov.za/LinkClick.aspx?fileticket=|AFqUox7XHU\%3D\&tabid=692\&mid=2607

Department of Basic Education \& Department of Higher Education \& Training. (2011). Integrated strategic planning framework for teacher education and development in South Africa: 2011-2025. Retrieved

from 
http://www.education.gov.za/LinkClick.aspx?fileticket=ZF\%2F6rDGMIFM\%3D\&tabid=358\&mid=2 $\underline{316}$

Francis, D. A. (2012). Teacher positioning on the teaching of sexual diversity in South African schools. Culture, Health \& Sexuality, 14(6), 597-611. http://dx.doi.org/10.1080/13691058.2012.674558

Francis, D. A., \& DePalma, R. (2015). 'You need to have some guts to teach': Teacher preparation and characteristics for the teaching of sexuality and HIV/AIDS education in South African schools.

SAHARA-J: Journal of Social Aspects of HIV/AIDS, 12(1), 30-38.

http://dx.doi.org/10.1080/17290376.2015.1085892

Gibbs, A., Willan, S., Jama-Shai, N., Washington, L., \& Jewkes, R. (2015). 'Eh! I felt I was sabotaged!': Facilitators' understandings of success in a participatory HIV and IPV prevention intervention in urban South Africa. Health Education Research, 30(6), 985-995.

Gubrium, J. F., \& Holstein, J. A. (2002). Handbook of interview research: Context and method. Thousand Oaks, USA: SAGE.

Harper, D. (1986). Meaning and work: A study in photo elicitation. Current Sociology, 34(3), 24-46. http://dx.doi.org/10.1177/001139286034003006

Harper, D. (2002). Talking about pictures: A case for photo elicitation. Visual Studies, 17(1), 13-26. doi: 10.1080/14725860220137345Helleve, A., Flisher, A. J., Onya, H., Mukoma, W., \& Klepp, K. I. (2009). South African teachers' reflections on the impact of culture on their teaching of sexuality and HIV/AIDS. Culture, Health \& Sexuality, 11(2), 189-204. http://dx.doi.org/10.1080/13691050802562613

Higher Education HIV/AIDS Programme (HEAIDS). (2010). HIV and AIDS in teacher education: Evaluation report of a pilot project in South African higher education institutions. Pretoria, South Africa: HEAIDS. Retrieved from http://hivhealthclearinghouse.unesco.org/sites/default/files/resources/iiep hiv and aids in tea cher education.pdf

Holderness, W. L. (2012). Equipping educators to address HIV and AIDS: A review of selected teacher education initiatives. SAHARA-J: Journal of Social Aspects of HIV/AIDS, 9(1), S48-S55. http://dx.doi.org/10.1080/17290376.2012.744901

Human Sciences Research Council (HSRC). (2014). South African national HIV prevalence, incidence and behaviour survey, 2012. Cape Town, South Africa: HSRC Press.

James-Traore, T. A., Finger, W., Daileader Ruland, C., \& Stephanie, S. (2004). Teacher training: Essential for school-based reproductive health and HIV/AIDS education, focus on sub-Saharan Africa. In YouthNet (Ed.), Youth Issues Paper 3. Arlington, USA: Family Health International.

Jansen, L. (2015, June 9). Teachers to be told how to teach about sex. IOL. Retrieved from http://www.iol.co.za/news/south-africa/kwazulu-natal/teachers-to-be-told-how-to-teach-about$\underline{\text { sex-1869387 }}$

Jonker, C. (2012). The experiences of students participating in an HIV/AIDS teacher education pilot programme (Doctoral dissertation, University of Pretoria, South Africa). Retrieved from http://repository.up.ac.za/bitstream/handle/2263/30434/dissertation.pdf?sequence=1

Khau, M., de Lange, N., \& Athiemoolam, L. (2013). Using participatory and visual arts-based methodologies to promote sustainable teaching and learning ecologies: Through the eyes of preservice teachers. The Journal for Transdisciplinary Research in Southern Africa 9(3), 401-412. Retrieved from http://reference.sabinet.co.za/webx/access/electronic journals/transd/transd v9 n3 a4.pdf 
Khau, M., Masinga, L., \& Pithouse, K. (2008, August). "Let's talk about sex, baby; Let's talk about you AND ME": Facing the challenges of including teachers' sevles in sexuality, HIV and AIDS education. Paper presented at the 7th international conference on the self-study of teacher education practices, Herstmonceux Castle, UK.

Kosnik, C. (2009). It is not just practice: Conflicting goals, unclear expectations, mixed messages. In F. J. Benson \& C. Riches (Eds.), Engaging in conversations about ideas in teacher education (pp. 6571). New York, USA: Peter Lang.

Lankshear, C., \& Knobel, M. (2006). New literacies everyday practices and classroom learning. Maidenhead, UK: Open University Press.

Lapenta, F. (2011). Some theoretical and methodological views on photo-elicitation. In E. Margolis \& L. Pauweles (Eds.), The Sage handbook of visual research methods (pp. 201-213). Thousand Oaks, USA: SAGE.

MacEntee, K. (2011, May). Participation in leadership: A critical analysis of participation in a youthbased collage workshop on HIV and AIDS in rural South Africa. Paper presented at the Comparative and International Education Society (CIES) Annual Conference, Montreal, Canada.

Masinga, L. (2014, August). Journeys to self-knowledge: A collaborative study of teachers as sexuality educators. Paper presented at the Tenth International Conference on Self-Study in Teacher Education Practices, Auckland, New Zealand.

Mitchell, C. (2014). FIRE+ HOPE UP: On revisiting the process of revisiting a literacy-for-social action project. In J. Sefton-Green \& J. Rowsell (Eds.), Learning and literacy over time: Longitudinal perspectives (pp. 32-45). New York, USA: Routledge.

Mitchell, C., de Lange, N., \& Moletsane, R. (2014). Me and my cellphone: Constructing change from the inside through cellphilms and participatory video in a rural community. Area, 1-7.

Mitchell, C., \& Smith, A. (2003). 'Sick of AIDS': Life, literacy and South African youth. Culture, Health \& Sexuality, 5(6), 1. http://dx.doi.org/10.1080/13691050110149909

Mitchell, C., \& Weber, S. (1999). Reinventing ourselves as teachers: Beyond nostalgia. Philadelphia, USA: Taylor \& Francis.

Naidoo, J. (2014). HIV/AIDS pedagogy and teacher emotions: The heart of the matter. In D. Francis (Ed.), Sexuality, society \& pedagogy (pp. 29-46). Bloemfontein, South Africa: Sun Press.

Orellana, M. F. (1999). Space and place in an urban landscape: Learning from children's views of their social worlds. Visual Sociology, 14(1), 73-89. http://dx.doi.org/10.1080/14725869908583803

Pithouse, K. (2011). Picturing the self. In L. Theron, C. Mitchell, A. Smith, \& J. Stuart (Eds.), Picturing research: Drawing as visual methodology (pp. 37-48). Rotterdam, Netherlands: Sense.

Pithouse, K., Mitchell, C., \& Weber, S. (2009). Self-study in teaching and teacher development: A call to action. Educational Action Research, 17(1), 43-62. http://dx.doi.org/10.1080/09650790802667444

Pithouse-Morgan, K., de Lange, N., Mitchell, C., Moletsane, R., Olivier, T., Stuart, J., ... Wood, L. (2013). Creative and participatory strategies for teacher development in the age of AIDS. In J. Kirk, M. Dembélé, \& S. Baxter (Eds.), More and better teachers for quality education for all: Identity and motivation, systems and support (pp. 75-93). Retrieved from http://moreandbetterteachers.wordpress.com/

Raht, D., Smith, J., \& MacEntee, K. (2009). Engaging youth in addressing HIV \& AIDS: Creative and participatory methods in the classroom. In C. Mitchell \& K. Pithouse (Eds.), Teaching and HIV \& AIDS (pp. 219-236). Johannesburg, South Africa: MacMillan. 
Schaefer, L., Downey, C. A., \& Clandinin, D. J. (2014). New possibilities for reimagining teacher education. In D. J. Clandinin, L. Schaefer, \& C. A. Downey (Eds.), Narrative conceptions of knowledge: Towards understanding teacher attrition (pp. 199-208). http://dx.doi.org/10.1108/S1479-368720140000023009

Shefer, T., Strebel, A., \& Jacobs, J. (2012). AIDS fatigue and university students' talk about HIV risk. African Journal of AIDS Research, 11(2), 113-121. http://dx.doi.org/10.2989/16085906.2012.698078

South African National AIDS Council. (2011). National strategic plan on HIV, STIs and TB2012-2016 summary. Retrieved from http://www.thepresidency.gov.za/MediaLib/Downloads/Home/Publications/SANACCallforNomin ations/A5summary12-12.pdf

Stuart, J. (2006). 'From our frames': Exploring with teachers the pedagogic possibilities of a visual artsbased approach to HIV and AIDS. Journal of Education, 38, 67-88.

Stuart, J. (2010). Youth as knowledge producers: Towards changing gendered patterns in rural schools with participatory arts-based approaches to HIV and AIDS. Agenda, 24(84), 53-65. http://dx.doi.org/10.1080/10130950.2010.9676309

Stuart, J., Raht, D., \& Smith, J. (2011). Youth as knowledg producers: Re-visioning teacher/learner roles through extracurricular activities. In F. Islam, C. Mitchell, N. De Lange, R. Balfour, \& M. Combrinck (Eds.), School-university partnerships for educational change in rural South Africa: Particular challenges and practical cases (pp. 163-171). Lewiston, USA: Edwin Mellen Press.UNAIDS. (2013). South Africa epidemiological fact sheet on HIV and AIDS. Retrieved from http://www.unaids.org/sites/default/files/epidocuments/ZAF.pdf

UNESCO. (2015). Comprehensive sexuality education in teacher training in Eastern and Southern Africa. Retrieved from http://hivhealthclearinghouse.unesco.org/sites/default/files/resources/cse in teacher training in esa.pdf

Van Laren, L. (2008). Exploration of strategies to integrate HIV and AIDS education in pre-service teacher education. African Journal of Research in Mathematics, Science and Technology Education, 12(1), 47-61. http://dx.doi.org/10.1080/10288457.2008.10740641

Van Laren, L. (2011a). Drawing in and on mathematics to promote HIV \& AIDS preservice teacher education. In L. Theron, C. Mitchell, A. Smith, \& J. Stuart (Eds.), Picturing research: Drawing as visual methodology (pp. 133-146). Rotterdam, Netherlands: Sense.

Van Laren, L. (2011b). Integrating HIV \& AIDS education in pre-service mathematics education for social justice. South African Journal of Education, 31(3), 333-344.

Van Laren, L. (2014). Beyond metaphor drawings to envisage integration of HIV \& AIDS education: A self-study in primary mathematics teacher education. Perspectives in Education, 32(2), 21-36.

Wilmot, D., \& Wood, L. (2012). In search of an enabling pedagogy for HIV and AIDS education in initial teacher education. South African Journal of Health Education, 26(5), 1112-1130.

Wood, L., \& Rolleri, L. A. (2014). Designing an effective sexuality education curriculum for schools: Lessons gleaned from the South(ern) African literature. Sex Education, 14(5), 525-542. http://dx.doi.org/10.1080/14681811.2014.918540 